\title{
Growing up in a Single Parent Family; A Determining factor of Adolescent's Well-being
}

\author{
Ajita Gupta \& Seema Kashyap \\ Dept. of Home Science, Faculty of Arts, Dayalbagh Educational Institute (Deemed University), \\ Agra- 282005, Uttar Pradesh, India \\ * Corresponding author email: gupta.aj50@ rediffmail.com
}

Received: 27 August 2020 / Revised: 10 November 2020 / Accepted: 28 November 2020 / Published: 06 December 2020

\begin{abstract}
Family is the backbone of all children and children are supposed to grow in a family setting where both mother and father plays their respective roles in providing them a sense of security and stability but when it is done single handedly it becomes quite difficult to perform up to the expectations. In recent years, there has been a sudden rise in the phenomenon of single parent families in India due to multiple factors including the influences from western society. The present article is an attempt to review the available literature on single parent families, their causal factors, strengths as well as its weaknesses. Furthermore, the positive and negative impact of single parenting on adolescent's physical, psychological, emotional, behavioral, educational and social wellbeing is also discussed in detail. Besides, this paper suggests few strategies for single parents so that they can easily manage and cope up with the difficulties they face in such situations which might be helpful in improving the wellbeing of their adolescent children.
\end{abstract}

Keywords: Single Parent Families, Adolescents, Wellbeing, Single Parenting.

\section{Introduction}

Family is the fundamental social group, comprising of parents and their children. Parents serves as a medium to provide all needed resources such as food, clothing, shelter, love, affection, health care, education, recreational facilities etc. All the members in a family discuss various things and share their thoughts and feelings i.e. happiness, sadness, fear, pain and problems with each other. Parents perform multidimensional operations for the wellbeing, welfare and development of their children. Parental roles are culturally and biologically determined. Amofa (2013) specified that maternal role is rearing and caring of children, home making and playing complimentary roles whereas paternal role is bearing economic responsibilities, providing basic necessities and discipline for the children. Yunus et al. (2012) stated that family system not only facilitates one to grow up, get socialized and find their own identity but also reflects the culture, values, expectations and rules of the society. Family therefore lays a bridge for the child to be a part of the society. Adolescence is the stage in which parents need to pay more attention and supervision because their future depends on the direction showed by them (Agnafors et al., 2019). Parents are responsible for overall development of their children by promoting their physiological, psychological, cognitive, emotional, moral, social and career development and also bringing up them as per the norms and values of the society (Ali \& Soomar, 2019). Nowadays, Single parenting is already becoming fast and rapidly growing trend in Indian society. According to Bhat and Patil (2019), "There are 320 million children between 0 to 17 years of age living with single parents globally and near about 2.3 million children are living with single parent in India." Mabuza et al. (2014) defined single parenting as "When one of two parents is not available for the nurturing and child rearing, the responsibilities meant for two people is being carried out by one person." Additionally, Chanda and Pujar (2018) explained single parenting as "The Family that comprise of single mother or father having their dependent children." 
Breakdown in the family structure leads all responsibilities of the family and upbringing of children in single hand that may have a tremendous impact on a child and their ability to function ordinarily. Therefore, present article is an attempt to draw some constructive conclusion on this sensitive and significant issue prevailing in the society with the objective of exploring the factors responsible for single parenting in India, its strengths and weaknesses, positive and negative impact of single parenting on their adolescents and managerial strategies for single parents to enhance the wellbeing of their adolescent children.

\section{Causal Factors of Single Parenting}

In Indian society, family breakdown is the root cause of single parenting. Causative factors for family breakdown are parental conflicts, financial hardship and parent-child relationships.

Parental conflict is a significant variable that mainly occur due to extra marital affairs, marriage against the wish of an individual or inability to adjust with each other that leads to separation or divorce which in turn negatively affect the children. Other reasons for single parenting are denied paternity and rape (Falana et al., 2012). Stephen and Udisi (2016) also specified some causative factors of single parenthood such as divorce, desertion, death of a partner, unintended pregnancy, single parent adoption and migration that leads to parenting in a single hand. Migration of spouse for extended period of time due to transfer, unemployment and other reasons lead all rearing and bearing responsibilities of children on the shoulders of another partner. Ali and Soomar (2019) stated that, there are many interrelated factors of family breakdown such as personal attributes, different social circumstances and even genetic aspects that may also contribute to the risk of divorce plus the teenage pregnancy also leads to forceful marriage which by time become causative factor for separations.

\section{Strengths and Weaknesses of Single parenting}

Like any other situation or condition, single parenting also has two sides i.e. either positive or negative which ultimately affects the wellbeing of their children. Some strengths and weaknesses of single parenting are discussed below:

\section{A. Strengths of Single parenting}

i. Share responsibilities: Single parents spend quality time with their adolescents that allows them to develop a strong unique bond (Guhasarkar, 2020; Raja, 2020). Children from single parent families realizes the importance of their parent's life and understand the value of their contribution. Then they give more respect and take extra care of their parents. Children learn to be responsible at a younger age and share numerous responsibilities of their parents (Synder, 2020).

ii. Manage finances solely: Single parents usually understand the value of money. They manage their finances independently. In the household, they take their financial decisions without conflict, argument and disruption from the partner. Single parents willingly spend, save and invest money to fulfill basic as well as emergency need of them and their children (Raja, 2020).

iii. Sense of Freedom and Self- dependency: Single parents in the household are usually free to make day to day decisions. They fulfil all responsibilities without negotiation or argument with the partner (Malachi, 2020). Raja (2020) also stated that single parents have entire authority or right for making all types of decisions. Due to sense of freedom, single parents feel confident and independent, they arrange family schedule and live their life according to their own choice.

iv. Less parental conflict: Strained and fighting relationships between parents negatively affects the entire family. Guhasarkar (2020) stated that absence of parental conflicts and argument release tension and calms the household environment thus it is an advantage for single parents that, there is no one around to contradict them over the welfare of the children. 
B. Weaknesses of Single parenting: Parenting done by both parents is challenging enough even under the best of conditions whereas single parents bear multifaceted challenges due to overburdens of responsibilities. Some weaknesses of single parenting are as follows:

i. Life stress and loneliness: Stress is a normal reaction that everybody experiences and channelize it in a different way but the family disruption can be more stressful than any other. Any change in the life even positive and negative can be stressful. Chanda and Pujar (2018) said that single parents have many responsibilities to deal. They have to handle several household tasks, have to take decisions by own and earning to nurture and support the children. Jackson et al. (2010) stated that single parents feel loneliness, helpless, hopeless, frustration, sleepless, familial distress, lack of identity and confidence.

ii. Economic hardships: Children learn best by receiving adequate learning, development materials and psychosocial support. In the adolescent period, there is a great need to invest more resources for higher education as well as for fulfilling other necessarily requirements of the adolescents. Financial responsibility is consequently being a big issue in single parent households. Families headed by single mothers are more likely to experience poverty due to the loss of a partner's finances, lower maternal educational attainment and discriminatory wages against women (Daryanai et al., 2016). Single parents face numerous challenges in meeting adequate financial and material resources i.e. providing good food, clothing, school fees, luxury items, mutual give and take with friends, difficulty in maintaining previous standard of living and paying back of loans taken by the partner. They also found trouble in fulfilling their liabilities personal expenses due to poverty, illness and unemployment (Ozturk \& Boylu, 2015; Elijah, 2017; Wajim \& Grace, 2020).

iii. Poor Mental health: Mental well-being of single parents has affected due to overloaded with work, family conflicts, life stress, availability of child care, frequent changes in family situations, food insecurity, housing and financial stress, unemployment, social isolation, weaker sense of community belonging or lack of social support, transportation and a lower household income (Banerjee, 2013). Due to these major difficulties, single parents face adjustment issues, anxiety disorders, eating disorders, addictive behaviors, depression, poor physical and psychological health and reduced ability to concentrate (Ifcher \& Zarghamee, 2014).

iv. Ample time for child rearing: Quality child rearing and caring means consistent response to children's signals, being available for communication, stress alleviation and creating a base for attachment bond with child. Single parents experienced difficulties in paying attention during sickness, disciplining them, helping in school assignments, choosing subject for their higher studies, taking them out for recreations like movies, picnics, trips and making arrangements for their wedding (Agnafors et al., 2019). Numerous responsibilities of children, household chores and earning cut the enough time of the parents. These circumstances might cause parents to be more impatient and irritable which can have an impact on their interactions with their children (Elijah, 2017).

v. Loss of parental support and supervision: Parent-child relationship contributes positively to the children's learning and development. Due to juggling between housing and working responsibilities, single parents may fail to supervise, control, monitor and guide socio emotional aspects which enhance school achievements and behavior of the children (Mugove, 2017). Ali and Soomar (2019) also stated that single parents does not able to spend quality time with their children in activities such as listening their concerns, understanding their emotional and psychological needs, helping in doing homework and asking about their studies. Many children therefore have feelings of inferiority, sadness, anxiety, anger, resentment, guilt, shame and depression about the future. 


\section{Positive and negative impact of single parenting on Adolescent's Wellbeing}

Available research indicated that both positive and negative effects of single parenting affect the wellbeing of adolescents. Malachi (2020) stated that adolescents of single parents have strong bonding, sense of community or support groups. They understand the value of parental contribution and learn to manage their disappointment in life. Adolescents of single parents balance their needs with the need of the family whereas in most of cases, they also have feeling of loneliness, financial crises, nourished with low parenting quality also have emotional problems and adjustment difficulties. These positive and negative effects of single parenting on adolescents are discussed as follows:

i. Psychological and Emotional Wellbeing: Marital separation involves major emotional trauma for child's relationship. At all age groups, the children behavior at home and school often deteriorates. It was observed that children aged six to eight react with grief, fear and intense longing for reconciliation whereas children of nine to twelve aged tend to be openly angry (Ifcher \& Zarghamee, 2014). Life of children in a single parent family can be traumatic, they suffer with poor self-concept and physical health (Cavanagh \& Fomby, 2012). Parental separation is very damaging condition to the self- concept of children, they experience feeling of embarrassment, confusion, emotional stress and depression (Mello et al., 2016), they also have emotional issues such as lack of warmth, discipline problems, hostile, hyperactive and aggressive (Richer \& Lemola, 2017). They found difficulties in school and also suffer from anxiety of uncertainties when their parental love is divided or distorted. On the other hand, it is also seen that children of single parents may grow into mature and well-balanced adults. They contribute and bear many responsibilities of parents on their shoulders (Raja, 2020).

ii. Educational Wellbeing: Education is considered as the first step for every human activity. It plays a vital role in the development of human capital and it is linked to an individual's wellbeing and opportunities for better living. Ishetu (2015) explored various socio-economic factors of parents that have been attributed to the poor academic performance of children i.e. parental education, income, nature of occupation, type of family structure, type of school, working conditions of the teachers and type of attention and involvement they get from their parents. Children's academic performance improves when both parents are actively involved in their education (Watt, 2019). On the contrary, Ushie et al. (2012) stated that there is no significant difference in the academic performance of adolescents from single parent families and those from two parent families.

iii. Behavioral Wellbeing: In the single parent family, it is hard to maintain discipline in the home which can contribute to rise in behavioral and psychosocial problems among adolescents such as smoking, drinking, delinquency and violence (Copeland, 2010), unsafe adolescent sexual activity, teen pregnancy and suicide attempts (Jackson et al., 2010). The absence of father is mainly associated with an increase in antisocial behaviors in boys including violence, criminality, substance abuse and decrease in social adjustment (Bornstein and Bradley, 2014). Adolescents of single parent families engaged in unconstructive and unacceptable behaviors such as violation, harming others and suicidal attempts to release tension or for the feeling of relief from their emotional pain (Mugove, 2017). On contrary, by seeing their parental hardworking adolescents also learn to express emotions and deal with problems of life. Adolescents also develop good sacraments and learn to manage their disappointments in life as well as they also get motivated to work along with their parents (Guhasarkar, 2020).

iv. Social Wellbeing: According to Cavanagh and Fomby (2012), "Single parenting is strongly associated with an increased risk of a number of negative social behavior and emotional outcomes for children." Bhat and Patil (2019) explored that participation in social and recreational activities were slightly lower in children of single parent families because of they might not getting socially acceptable and desirable responses. The socialization of children is 
therefore very vital for the continuity of any culture, the process of socialization generally depends on both parents who plays complementary roles in bringing up the child. Children of single parents do better when they receive strong support from nearby relatives, friends, neighbors, members of religious groups, staff members of family support and child care programs (Synder, 2020). Stephen and Udisi (2016) also stated that children are raised in highly structured and disciplined manner in most communities because their parents helped to inculcate strong basic moral, spiritual and social principles in their children.

\section{Management strategies for Single Parents}

Single parents usually face various challenges and problems while rearing their children. These problems would not vanish magically but can be controlled, managed and sorted up to an extent by using some strategies. Description of some managerial strategies for single parents is given following:

i. Mutual Understanding: Death is one of the most accepted stressful life events for single parents. The survivor not only survive and adjust with the loss of close relationship but also try to manage the responsibilities which were shared by both of them. However, the other causal factors of single parenting can be controlled by various ways. Marital disunity is a major cause of single parenting (Watt, 2019). Forces of disunity should be ignored and de-emphasized if not eliminated. Whenever there is a problem in the home, parents should appreciate, tolerate, understand and focus on each other's positive aspects as well as ignore the negative aspects of soulmates to maintain healthy relationships (Yunus et al., 2012).

ii. Time investment on children: Being able to parent a child is one of the biggest blessings in the world. It is a complex task consisting of the responsibility of children's physical, mental, intellectual and social health. Spending time is the best way to involve with child. Single parents should manage their time in such a way that they would be able to spend time in activities related to their children. Activities such as child care, education, helping in homework, visiting in children's schools, attending child's performances, having meal together etc. (Abudu \& Fuseini, 2013). Children of single parents should also be encouraged on three basic dimensions of selfconcepts i.e. sense of belonging, sense of worth and sense of competence. By investing time with children, single parents can also overcome from the feeling of loneliness.

iii. Wise use of monetary resources: Financial considerations are more valuable or essential element in the life of single parents. Single parents can also reduce wastage of money by controlling the purchase of useless or unnecessarily goods and services. They should therefore make a monthly budget plan to get a clear picture on the total expenditure of household. With the help of making budget, parent achieve an idea regarding the income and expenditure so that they can also make balance between income and expenditure. Single parents need to save and invest their monetary resources for emergencies and future safety (Stack \& Meredith, 2018).

iv. Development of a support system: Social support provided from friends, peers and other wellwishers may also lead to positive effects on single parents as well as on their children. Friends, relatives and family members seems to be a greater source of support. Single parents can also reduce the stress and tensions by sharing their feeling, pain and problems to their supporters. Single parents should therefore make helping hands or trustworthy friends in their life to recover early from the loss of their partner as well as to get emotional support for maintaining the life easily (Malachi, 2020).

v. Role of School administration: School administration can improve the situation of single parent families by motivating and sharing the information and experiences. Mugove (2017) stated that school administration should organize support groups time to time as well as schools should also set a guidance and counseling platforms for assisting and coping up with academic problems and other difficulties of children who belong to single parent families. Agnafors et al. (2019) said 
that the importance of schooling should be emphasized and they indicated the need for societal support to encourage adolescents to remain in school.

vi. Role of counselors: Both parents should try to stay together for the sake of good upbringing of their children. In the difficult, unavoidable and problematic situations, both parents can take help from the counsellor and psychologist for settling the problems between them. In case of single parenting, counselors and psychologist should also provide the necessary assistance and psychological support to single parents and their children to overcome their emotional problems (Nieuwenhuis, 2020).

vii. Role of welfare organizations and associations: There is an excessive necessity of NonGovernmental Organizations (NGO's) and Community Welfare Associations to help single parent families by managing credit facilities at affordable rate of interest through formal financial institutions (Wajim \& Grace, 2020). There is also a need to spread awareness on the issues of family planning, family values, parenting, parental skills, child discipline and effect of family on their own life as well as the children's life. These organizations can also assist the work by organizing awareness camps and programs in the society.

viii. Financial Stability through various government programs: Many single parent families face financial crisis for rearing and bearing the needs of the children. Single parents need a training for skill development and income generations. Government should therefore start an income generating and skill development programs for financially unstable parents to empower them so that they can nourish their children by providing necessarily resources. Nieuwenhuis (2020) also suggested that government should provide financial support in the form of insurance, pension and low interest loan schemes or policies to cope up economic problems. Government should also take initiative by starting educative programs on a national level through radio, television and other mass media for improving and sustaining two parent families.

\section{Conclusion}

In the contemporary times, parenting becomes very difficult task for both parents whereas breakdown or family disruption of any family system is tough. Nowadays, single parenting is becoming common whether by choice or because of divorce, separation or death of a spouse. Whatever the reason is, single parents face countless challenges. It does not only affect the parents but also affects the children. There are many short term and long-term effects of family disruption on the adolescents. In short term effects, adolescents are likely to suffer a variety of physical and emotional problems like intense anger, fear about future, loyalty conflicts, health problems, academic problems, withdrawal, depression, drug abuse, lack of social competence and early indulgence in sex while in long term effects, adolescents tend to attain less education, marry at an early age and have a less stable marriage due to lack of trust and happiness. Existing literature also has been found positive as well as negative impact on self-concept, physical development, personal relations, behavior, educational success, social integration and romantic relationship outcomes, recreational activities and career development on the adolescents of single parents. Single parents therefore, require a lot of courage, determination and emotional strength to overcome. They also need to carefully select the parenting practices and take the responsibilities with confidence to nurture the children. Warmth and affection given by parents has also been played an important role in increasing self-esteem, coping abilities and decrease anxiety among children. Family based intervention programs therefore should be designed by the government for single parents, dual parent families and their children to develop skills for strengthening family relationships and wellbeing of the children. There is also need to develop the capacities to cope up with problematic life situations and to become responsible citizens of the nation.

\section{Competing Interests}

The authors declared that no conflict of interest exist in this publication. 


\section{How to Cite this Article:}

Gupta, A., \& Kashyap, S. (2020). Growing up in a Single Parent Family; A Determining factor of Adolescent's Wellbeing. Advanced Journal of Social Science, 7(1), 138-144. https://doi.org/10.21467/ajss.7.1.138-144

\section{References}

Abudu, A.M., \& Fuseini, M.N., (2013). Influence of Single Parenting on Pupils' Academic Performance in Basic Schools in the WA Municipality. International Journal of Education Learning and Development, 1(2), 85-94.

Agnafors, S., Bladh, M., Svedin, C.G., \& Sydsjo. G., (2019). Mental health in young mothers, single mothers and their children. BMC Psychiatry, 19(112), 1-7. Retrieved from: http://doi.org/10.1186/s12888-019-2082-y.

Ali, S.K., \& Soomar, S.M., (2019). Single Parenting: Understanding Reasons and Consequences. JOJ Nursing and Health care, 10(2), 001003. Retrieved from: DOI: 10.19080/JOJNHC.2019.10.555781.

Amofa, R.A., (2013). Effects of Single Parenting on Adolescents Academic Performance. University of Cape Coast Faculty of Social Sciences Institute for Development Studies, 1-23.

Banerjee, A., (2013). The Mental Health of Single Parents in Canada: Do Gender and Geography matter? Retrieved from: http://citeseerx.ist.psu.edu/viewdoc/download?doi=10.1.1.1002.5340\&rep=rep1\&type=pdf.

Bhat, N.A., \& Patil, R.R., (2019). Single Parenthood Families and their impact on children in India. Delhi Psychiatry Journal, 22 (1), 161-165.

Bornstein, H., \& Bradley, H., (2014). Socioeconomic status, parenting and child development. Journal of Early Adolescences.

Cavanagh, S.E., \& Fomby, P., (2012). Family Instability, School Context, and the Academic Careers of Adolescents. Sociology of Education, 85(1), 81-97. Retrieved from: DOI: 10.1177/0038040711427312.

Chanda, K., \& Pujar, A., (2018). Stress and Psychological Wellbeing among Single parents. International Journal of Pure and Applied Bioscience, 6(4), 226-232. Retrieved from: Doi: http//dx.doi.org/10.18782/2320-7051.6692.

Copeland, D. B., (2010). Psychological differences related to parenting infants among single and married mothers. Issues in Comprehensive Pediatric Nursing, 33, 129-148.

Daryanai, I., Hamilton, J.L., Abramson, L.Y., \& Alloy, L.B., (2016). Single Mother Parenting and Adolescent Psychopathology. J Abnorm Child Psychol, 44(7), 1411-1423. Retrieved from: doi:10.1007/s10802-016-0128-x.

Elijah, J., (2017). Challenges every Indian Single Parent Faces. Retrieved from: https://www.youthkiawaaz.com/2017/10/single-indianparents-things-we-need-to-understand/

Ifcher, J., \& Zarghamee, H., (2014). The happiness of single mothers: Evidence from the general social survey. Journal of Happiness Studies, 1(5), 1219-1238. Retrieved from: doi:10.2139/ssrn.1740029.

Ishetu, A.A., (2015). Does School Type Matter in Academic Achievement in Regional Examination? Comparative Study of Private and Government Schools in Dessie Administrative Town. North Central Ethiopia International Journal for Educational Studies, 7(2), 161170 .

Falana, B.A., Bada, F.O., \& Ayodele, C.J., (2012). Single-parent Family Structure, Psychological, Social and Cognitive Development of Children in Ekiti State. Journal of Educational and Developmental Psychology, 2(2), 158-164.

Guhasarkar, S., (2020). The influence of Negative and Positive Parenting on Children. Retrieved from: https://www.momjunction.com/articles/influence-of-negative-and-positive-parenting-on-children_00119750/.

Jackson, A. P., Preston, K. S., \& Franke, T. M., (2010). Single Parenting and Child Behavior Problems in Kindergarten. Race and Social Problems, 2, 50-58. Retrieved from: Doi:10.1007/S12552-010-9026-Y.

Mabuza, N., \& Thwala, S.K., \& Okeke, (2014). Single Parenting and Its Effects on the Psychosocial development of children in Swaziland. Mediterranean Journal of Social Sciences, 5(23).

Malachi, R., (2020). Positive and Negative effects of Single Parenting. Retrieved from: http://www.momjunction.com/articles/effect-ofsingle-parenting_00373930/

Mello, L.D., Govindaraju, B.M., \& Monteiro, M., (2016). A Study on the Challenges Faced by Single Parent on Teenager Care. International Journal of Advanced Trends in Engineering and Technology, 1(1), 54-59.

Mugove, K., (2017). Challenges Encountered by Single Parents in the Learning and Development of Children, International Journal of Scientific and Research Publications, 7(6), 178-186

Nieuwenhuis, R., (2020). Directions of thought for single parents in the EU. Routledge, 1-8. Retrieved from: https://doi.org/10.1080/13668803.2020.1745756.

Oztruk, M.S., \& Boylu, A.A., (2015). Investigation of Economic Activities of Single Parent Families. Sosyoekonomi, 23(25), 93-111. Retrieved from: DOI: $10.17233 / \mathrm{se} .13693$

Raja, D., (2020). Advantages and Disadvantages of single parenting. Retrieved from: https://www.momjunction.com/articles/advantages-anddisadvantages-of-single-parenting_00372990/.

Richter, D., \& Lemola, S., (2017). Growing up with a single mother and life satisfaction in adulthood: A test of mediating and moderating factors. PLoS ONE, 12(6),1-15. Retrieved from: https://doi.org/10.1371/journal.pone.0179639.

Stack, R.J., \& Meredith, A., (2018). The Impact of Financial Hardship on Single Parents: An Exploration of the Journey from Social Distress to Seeking Help. J Fam Econ Iss, 39, 233-242. Retrieved from: DOI 10.1007/s10834-017-9551-6,

Stephen, E.N., \& Udisi, L., (2016). Single-Parent Families and their impact on children: A study of Amassoma Community in Bayelsa State. European Journal of Research in Social Sciences, 2(9), 1-24.

Ushie, M.A., Emeka, J.O., Ononga, G.I., \& Owolabi, E.O., (2012). Influence of family structure on Students' academic performance in Agege Local Government Area, Lagos State, Nigeria. European Journal of Educational Studies, 4(2), 177-187.

Wajim, J., \& Grace, S.H., (2020). Single Parenting and Its Effects on the development of Children in Nigeria. The International Journal of Social Sciences and Humanities Invention 7(03): 5891-5902. Retrieved from: DOI:10.18535/ijsshi/v7i04.02.

Watt, A., (2019). Single Parent Households and the Effect on Student Learning. Masters Theses (4464), 1-59. Retrieved from: https://thekeep.eiu.edu/theses/4464

Yunus, G., Fatma, S.T., \& Haktan, D., (2012). Functions of The Family: Family Structure and Place of Residence. Eest Part B Social and Educational Studies, 4(1), 549-556. 